\title{
Opportunities and Challenges in the Health and Nutrition Industry with the Rise of Younger Consumers
}

\author{
Qunyi Zheng
}

\begin{abstract}
Health awareness was becoming a social priority even before the COVID19 pandemic, especially among younger people in China. This is due to factors like better living standards, improved health awareness and greater emphasis on nutrition and health. But the nutrition and health market in China is also undergoing profound changes. Snacks are replacing lunch and dinner, e-commerce is a major driver of change and sports nutrition is becoming increasingly important. Herbalife is working to meet this changes head on and ensure a healthier China.
\end{abstract}

Keywords Improved health awareness $\cdot$ Better living standards $\cdot$ Greater emphasis on nutrition and health $\cdot$ e-Commerce $\cdot$ Sports nutrition

HEALTH became a keyword and the hottest topic during COVID-19, which has greatly enhanced people's awareness of the importance of health. There is a trend among Chinese people to attach more significance to personal nutrition and health, and choose to live healthy, balanced lives, which, in the long-term, will create huge opportunities for the health and nutrition industry.

Health awareness was becoming a social priority even before the COVID-19 pandemic, especially among younger people in China. This article focuses on the opportunities and challenges that China's health and nutrition industry faces as the influence of young consumers increases.

\section{Youth Demographics-An Important Driving Force of China's Health and Nutrition Industry}

The "Youth Demographic" is usually categorized into two groups of people: Millennials (born between 1980 and 1994) and Generation Z (born between 1995 and 2009).

Q. Zheng $(\bowtie)$

Herbalife China, Shanghai, China 
Many people imagine the majority of consumers interested in nutrition and health products to be middle-aged and elderly people-i.e. "Baby Boomers" and "Gen Xers", but increasing evidence shows that today's young people are realizing the importance of health much earlier in life than their parents. They have become an important driving force in health and nutrition and will create great opportunities for the industry.

According to a CCTV Finance report from October 2020, ${ }^{1} 25 \%$ of those who purchased nutrition and health products were born after 1990. Data from the 2019 Report on Interest in the Health Products Industry show that more than $60 \%$ of individuals who expressed interest in health products were born after $1990 .^{2}$ Analysis from Herbalife Nutrition's sales figure also proves this-in China, more than $80 \%$ of Herbalife Nutrition's target customers were millennials, while $25 \%$ were from Generation Z.

Younger generations are increasingly incorporating nutrition products into their health regimens and they are becoming important powerhouses for market growth. The main reasons behind this include the following:

(1) Economic development and better living standards inspired consumption. GDP growth and increases in per-capita income have resulted in increased purchasing power among the general population. In addition to education, young people also tend to spend more money on sports, entertainment and health, and nutrition. On the macroeconomic level, the Chinese government has also taken measures to promote consumption in this area.

(2) Improved health awareness and literacy among Chinese citizens. According to statistics from China' National Health Commission, health awareness and literacy among Chinese people has increased from $10.25 \%$ to $19.17 \%$ over the past five years. ${ }^{3}$

The convenience of communication brought about by the Internet and smartphones has enabled younger generations to easily access abundant information on health and nutrition and build a deeper understanding of nutrition compared to previous generations.

In a survey jointly conducted by Herbalife Nutrition and the NGO Feed the Children in early 2021 in China, more than $90 \%$ of people aged between 18 and 40 were familiar with the term "balanced/unbalanced nutrition". Meanwhile, 63\% of Gen Zers and $80 \%$ of millennials were familiar with the "National Nutrition Guidelines", while this percentage among the $57+$ group was only $50 \%$.

A wealth of nutrition and health knowledge as well as a deeper understanding of the scientific nature of supplements has caused more young people to consider using nutritional supplements to improve their health.

\footnotetext{
${ }^{1}$ Post- $90 \mathrm{~s}$ become the main purchaser of supplements, bringing a steady growth in its market size, https://tv.cctv.com/2020/10/20/VIDEEunFLBUmJNpB7RWGcXNr201020.shtml.

${ }^{2}$ Annual Website Visibility Analysis Report of Health Care Industry 2019, https://xw.qq.com/cmsid/ 20200407A086XK00.

${ }^{3}$ National Health Commission: China's health literacy rate has risen from $10.25 \%$ to $19.17 \%$, https:// baijiahao.baidu.com/s?id=1685754124375725801\&wfr=spider\&for=pc.
} 
(3) Young people's unique lifestyles lead to attach greater importance to nutrition and health. Chinese young people are generally faced with a fast-paced, highintensity work environment. Many people experience chronic stress and their daily routines are irregular. This has caused extensive "health anxiety", and the "National Health Insight Report 2020"4 shows that of all groups surveyed young people were the most anxious about their health.

When asked about what their "Top New Year's Wish" was, most Chinese young people said that they wanted to "live a healthier life/stay in good shape", which ranked far higher than "more travel during holidays" and "making more money". 5

As the pressure of life conflicts with their ideal lifestyle, more and more young people have started to seek help, turning to nutritional products. The consensus among younger demographics is to "have a healthy life as early as possible".

\section{Meeting the Needs of Young People}

With younger demographics becoming a driving force, the nutrition and health market in China is also undergoing profound changes.

(1) Snacks as lunch or dinner: With a faster work pace, many people, especially white-collar youth, find that they sometimes don't have enough time to enjoy lunch or dinner. Travel, tight schedules, and unplanned circumstances can make it almost impossible to ensure a well-balanced diet. To a certain extent, snacks have gradually replaced the function of lunch or dinner.

This has resulted in the idea of "meal replacement". Meal replacement was originally the result of necessity in clinical settings for patients who could not ingest regular food due to physical impairments or additional calorie demands.

However, the convenience of meal replacements like calorie-controlled, prepackaged food, such as bars and beverages, can offer an alternative to regular meals. This allows consumers to enjoy nutritious and quick meals, and is experiencing rapid growth in the Chinese market. It is possible that healthy snacks and meal replacements may become a "rigid demand" among young people in the future and an important part of daily life.

Focusing on the huge demand for "nutritious and convenient meals", many health product companies have already begun to come up with solutions. Today, there are numerous meal replacement products on the market, available just about everywhere from supermarkets to online stores.

\footnotetext{
${ }^{4}$ Dingxiang Yisheng (an online medical service platform run by the medical website of www. DXY.cn) releases the National Health Insight Report 2020, with psychological problems becoming the focus of attention, https://www.chinanews.com/business/2020/01-15/9060347.shtml.

${ }^{5}$ Young people have emerged as a force of healthy consumption? The era of universal nutrition has arrived, https://www.sohu.com/a/453231243_121012870.
} 
According to the CBN Data Report "2020 Meal Replacement and Light Dinner Consumption Insight", the number of Chinese meal replacement brands in 2019 was 2,837 , and increased to as many as 3,540 in $2020 .^{6}$

As a leading brand in the nutrition industry since 1980, Herbalife Nutrition has been on a mission to improve nutritional habits around the world with great-tasting, science-backed nutrition products that help people get the right balance of healthy nutrition. As many as 4.86 million Herbalife Nutrition protein shakes are consumed daily worldwide.

Herbalife is focusing on improving its protein shakes so that they are more convenient and able to meet new market demands. In 2020, we launched a new protein drink mix with portable and easy-to-use packaging and localized flavors like red bean and coix seed for China. This was developed by the Herbalife China Product Innovation Center (CPIC), which is a key source for new products designed to serve China's changing nutrition needs.

Another replacement option is our healthy snack, "Protein Bites", which is popular among young consumers. Launched just last year, this product is a healthy option that people can eat at home, at work or on the go.

Dietary habits are constantly changing in today's China and Herbalife hopes to make our products more convenient and shareable to keep young people healthy.

(2) E-commerce: E-commerce has profoundly changed people's shopping habits. Each industry is exploring options to upgrade business models in conjunction with digitalization.

On November 11, 2020, also known as Singles' Day in China, the e-commerce platform T-mall exceeded RMB 498.2 billion in sales, up 26 percent year on year. ${ }^{7}$ The online retail sales of physical goods in China reached RMB 9.8 trillion Yuan (about USD1.52 trillion) in 2020, making the country the world's largest online retail market for eight consecutive years. ${ }^{8}$

Today's young people, especially the "Gen Z" group, is a generation that has grown up living with rapid economic development and the Internet. For health and nutrition companies, young consumers are very different from previous generations and we need to adapt to emerging needs by integrating both online and offline channels.

Digital transformation has been one of Herbalife Nutrition's most important strategies in China. In 2019, we partnered with Tencent to launch our digital transformation initiatives. In our industry, we are working to empower service providers to establish better connections with customers and adapt to their shopping habits. Integrated online and offline channels can better serve customers and optimize their shopping experiences, one of which is our personalized "Nutrition Store" which was launched on WeChat at the end of 2019.

\footnotetext{
${ }^{6}$ Young people who want to achieve the goal of weight loss by eating "healthy food" have boosted the meal replacement market with a turnover of 100 billion, https://baijiahao.baidu.com/s?id=168 $8015022322601375 \& w f r=$ spider $\&$ for $=$ pc.

${ }^{7}$ Tmall's turnover exceeded 498.2 billion yuan during the "Double 11" of 2020, https://baijiahao. baidu.com/s?id=1683127359801704277\&wfr=spider\&for=pc.

${ }^{8}$ China has been the world's largest online retail market for 8 consecutive years, http://www.gov. cn/xinwen/2021-01/19/content_5581163.htm.
} 
Our digital transformation initiative was one of the most important moves we took to ensure business operations remained stable during the COVID-19 epidemic in 2020. Early in the year, COVID-19 prevention and control requirements meant that Herbalife service providers couldn't meet face-to-face with customers, which affected the consumer experience. To address this issue, we trained distributors on how to efficiently interact and serve customers using the "Nutrition Store" platform. We also encouraged them to organize live broadcasts to provide customer service and online training.

(3) Sports Nutrition: Sports nutrition products have also become increasingly popular in recent years. Our target Chinese consumers, mainly in younger demographics, have gradually expanded from professional athletes to the general public.

This trend has been growing for a number of years. In October 2016, the Chinese government announced its "Healthy China" initiative, which made public health a focus for future economic and social development. In September 2019, the government also created national guidelines titled "An Outline for Building a Leading Sports Nation", which targeted wider public participation in sports, a stronger sports industry, and a more vibrant sporting culture.

We are seeing an increase in the number of Chinese people working to develop healthier lifestyles and getting involved in regular exercise. They are becoming healthier and more conscious about personal fitness. They are also making sports nutrition products a part of their daily diet because of the health benefits they bring.

China's sports nutrition market is driven by an increasing demand for sports nutrition supplements, not only among professional athletes but also fitness buffs and ordinary people. According to statistics from Euromonitor, China's sports nutrition market is expected to reach USD 859 million in 2023, with an annual increase of $24 \%$ from 2019 to $2023 .{ }^{9}$

Herbalife entered the sports nutrition market in China with the goal of meeting the needs of younger, fit and active consumers. Our main offering is the Herbalife 24 series of products, which began production in Nanjing in 2020. Herbalife24 is a comprehensive performance nutrition series empowering athletes 24 hours a day. We have surpassed industry standards for pre-, during- and post-workout nutrition products to help athletes train, recover, and perform with all the nutritional support they need.

The overwhelming amount of scientific evidence on the positive effects of sport and physical activity as part of a healthy lifestyle has inspired Herbalife to focus on promoting sport as an integral part of life that everyone should be participating in.

Globally, we have sponsored over 200 world-class athletes, teams, and events. We have been honored to sponsor the soccer player Cristiano Ronaldo since 2013 to fuel his quest for greatness.

Herbalife China has also donated RMB 9.05 million to the Beijing Sport University Education Foundation in 2019 to establish the Herbalife Nutrition Ice \& Snow

\footnotetext{
${ }^{9}$ Market analysis of the sports nutrition industry in China 2019: the explosive growth of the number of those doing sports is the core driver, http://www.leadingir.com/trend/view/3484.html.
} 
Development Fund, part of which is being used to establish a Herbalife Nutrition Winter Sports Nutrition Research Center. These research results will benefit not only professional athletes, but also help provide experimental data and sports nutrition data for fit and active groups in the general public.

In the future, Herbalife will continue to leverage its global experience and expertise in sports nutrition and provide Chinese customers with products that give them the nutrition they need and support them in living an active, healthy lifestyle.

\section{Supporting the Sustainable Development of the Nutrition Industry}

The continued improvement in Chinese people's living standards and increased demand for health related products has ushered in a sustained period of growth in the nutrition and health products market.

The health of individual members of society is closely related to their basic understanding of health. This has become an issue that affects China's development in a broad and comprehensive way, which means that it must be examined in the context of overall economic and social development as well as public policy. The "Healthy China" strategy is a key government program to promote healthy living in China and resolve some of the issues facing China's health sector. It also aims to provide practical means to achieve high-quality economic development and coordinated and sustainable economic and social development. In recent years, the Chinese government has implemented a number of policies in this area and by 2030, China's health industry is expected to exceed RMB 16 trillion.

I believe that in China, a fully activated market of 1.4 billion people with health needs is a huge market that will produce many experimental and innovative brands. Herbalife is undoubtedly committed to becoming one of them.

The COVID-19 pandemic has caused consumers to place greater emphasis on nutrition and health, with a growing demand for health products. Herbalife's net sales in 2020 were approximately USD 5.5 billion and increased by $13.6 \%$ year-onyear, marking the best annual sales record in our history. Meanwhile, three of our six global regions-Asia Pacific, EMEA (Europe, Middle East, and Africa), and North America - also set new annual sales records. In 2020, Herbalife's net sales in China reached about RMB 5.217 billion with a year-on-year increase of 7.7\%, accounting for $14 \%$ of global sales.

China's late entry into the health industry means that efforts in innovation and $R \& D$ remain behind other countries. Compared with the global environment, industry supply chains remain immature and development lacks synergy. China also lacks mature products and high-quality management systems. Its emerging meal replacement industry also urgently needs to develop corresponding regulations to standardize definitions, quality requirements, and labels for meal replacement products. 
The industry as a whole needs to work together to drive technological innovation, regulate the market, and drive the sustainable development.

In 2019, the China Nutrition Society issued its "Meal Replacement Group Standard" (T/CNSS 002-2018) in response to industry growth and as an important step toward establishing regulations and standards on meal replacement products.

In 2020, Herbalife Nutrition participated in the compilation of a book titled International Meal Replacement Policies and Regulations to help drive the standardization and healthy development in the meal replacement industry. We hope that this will help to bridge the gap between standards on nutrition and meal replacements across markets.

\section{Quality is at the Heart of Everything We Do}

Data from the China Nutrition and Health Food Association show that there were over 5,000 kinds of health foods claiming to enhance immunity as of 2019. With such fierce market competition, quality is essential and efforts to improve and maintain quality are how we maintain our core competitiveness and is the cornerstone of our survival and sustainable development.

One of our core quality assurance programs is our Seed to Feed quality management program. The Seed to Feed process encompasses everything from sourcing only the finest ingredients to meeting or exceeding good manufacturing practices. It is a 14-step quality control system through which we continuously test our products, putting them through an arduous protocol to ensure they comply with the highest quality standards.

Three of Herbalife Nutrition's five manufacturing facilities are based in China. Our two factories in Suzhou and Nanjing, which produce powders and tablets, and our botanical extraction facility in Changsha, are all integral to our Seed to Feed strategy. Herbalife also leads the industry in the area of botanical identification as we expand and improve our program to include new advances in areas like DNA technology.

Herbalife Nutrition is also working toward coming up with new products and remains committed to continuously expanding its product portfolio in China. In 2020, we launched 18 new products, the largest number since entering into the Chinese market. Moving forward, we will continue to focus on improving the convenience of product use, diversification of flavors as well as healthy snacks.

\section{Working Together for a Healthier China}

Regardless of the industry or country of origin, any company in China should be committed to providing quality products or services that benefit the consumers here. As a nutrition company, this is what we are working to do, both in terms of the 
products that we provide and sell, as well as our participation in programs that promote health and nutrition throughout China's diverse society.

At the national level, in March 2021, the 14th Five-Year Plan (2021-2025) for National Economic and Social Development and Long-Range Objectives Through the Year 2035 were officially announced. An important objective of the 14th FiveYear Plan is to build a "Healthy China", which proposes that China "accelerate the development of the health industry" and "support Chinese people in developing a healthy lifestyle".

This is the spirit with which we have approached our 20 years in China and the blending of national policy, the well-being of our end consumers, and the development of our business here are something that we take great pride in.

Development comes with both challenges and opportunity. Overall improvements in the standard of living among Chinese people come with certain risks including increased stress and less-than-healthy lifestyles. We serve the needs of a wide cross-section of society, from China's growing elderly population to the needs of young consumers, who are becoming increasingly health aware. All of these factors contribute to a promising future for China's health and nutrition industry.

As a global nutrition company providing health and wellness products to millions of people in 94 countries around the world, Herbalife Nutrition, with our global experience and expertise, is in a unique position to help Chinese people reach their health goals and contribute to the "Healthy China" initiative.

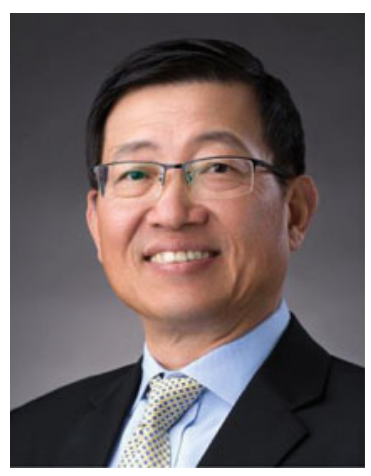

Qunyi Zheng is Senior Vice President/Chairman of Herbalife China. Dr. Zheng joined Herbalife Nutrition in 2010 as Vice President in Natural Product Manufacturing. In 2015, Dr. Zheng assumed responsibility of Vice President for Worldwide natural products Research, Development and Scientific Affairs. In 2017 Dr. Zheng was appointed as the Acting MD of China until January 2018 and currently is the Senior Vice President/Chairman of Herbalife China. Before joining Herbalife Nutrition, Dr. Zheng was the Founder of NatSource Chemicals Corporation, with which Herbalife Nutrition formed a joint venture to build its extraction facility in Changsha. Prior to this, Dr. Zheng was President of Kent Financial Services, Inc (NASDQ: KET) and President of Pure World, Inc (NASDQ: PURW). Dr. Zheng holds a Bachelor of Science degree in chemical engineering from Hunan University of China. He received a doctoral degree in chemistry from the University of Colorado and conducted post-doctoral research at Cornell University. Dr. Zheng is a leading expert in the supplements industry and he has led innovation and research of natural product extraction and developments for use in food, supplements, and pharmaceuticals. He has over 20 patents and 40 scientific publications. 
Open Access This chapter is licensed under the terms of the Creative Commons AttributionNonCommercial-NoDerivatives 4.0 International License (http://creativecommons.org/licenses/bync-nd/4.0/), which permits any noncommercial use, sharing, distribution and reproduction in any medium or format, as long as you give appropriate credit to the original author(s) and the source, provide a link to the Creative Commons license and indicate if you modified the licensed material. You do not have permission under this license to share adapted material derived from this chapter or parts of it.

The images or other third party material in this chapter are included in the chapter's Creative Commons license, unless indicated otherwise in a credit line to the material. If material is not included in the chapter's Creative Commons license and your intended use is not permitted by statutory regulation or exceeds the permitted use, you will need to obtain permission directly from the copyright holder.

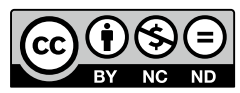

